PELATIHAN PEMBUATAN ZAT WARNA ALAM DAN APLIKASINYA UNTUK BATIK DI UMKM BATIK MANGGAR GADING

\title{
TRAINING OF NATURAL DYES PRODUCTION AND ITS APPLICATION FOR BATIK AT BATIK MANGGAR GADING SMES
}

\author{
Diah Pratiwi*, Cici Darsih \\ Balai Penelitian Teknologi Bahan Alam (BPTBA) \\ Lembaga Ilmu Pengetahuan Indonesia (LIPI) \\ email:ㄹee.diahpratiwi@gmail.com
}

\begin{abstract}
Abstrak
Batik zat warna alam memiliki beberapa kelebihan dibandingkan dengan pewarna sintetis. Pemberdayaan masyarakat ini dilakukan melalui dua kegiatan yaitu survei lapangan dan pelatihan. Survei lapangan dilakukan untuk mengidentifikasi dan mengumpulkan informasi terkait proses produksi di UMKM Batik Manggar Gading. Sementara itu, pelatihan yang diselenggarakan di UMKM Batik Manggar Gading terdiri dari dua jenis pelatihan. Pelatihan pertama, peserta diberikan pengetahuan tentang potensi bahan alam yang dapat digunakan sebagai pewarna kain dan praktek cara mengekstrak/ membuat zat warna alam. Pelatihan yang kedua, disampaikan materi tentang pengaplikasian zat warna alam pada proses pewarnaan kain batik. Batik pewarna alam merupakan suatu hasil perpaduan dari kegiatan pemanfaatan keanekaragaman hayati dalam mendorong pendapatan ekonomi masyarakat. Batik pewarna alam bisa menjadi produk unggulan Indonesia khususnya Gunungkidul di pasar Internasional.
\end{abstract}

Kata kunci: UMKM, batik, Manggar Gading, pewarna alam

\begin{abstract}
Natural dyes has some advantages than synthetic dyes. The develompent of knowledge and skills in production process of batik natural dyes is expected to increase income and livehood of batik craftsmen. Community empowerment is made through two activities, namely field survey and training. Field survey was conducted to identify and collect relevant information about production process in Batik Manggar Gading SMEs. Meanwhile, the training was held at Batik Manggar Gading SMEs consists of two types of training. The first training, participants are given the knowledge about the potential of natural ingredients that can be used as natural dyes and practice how to extract/ create a substance the color of nature. The second, participant are given training about deployment process of batik coloring used natural dyes. Natural dyes batik is a result of the utilization of biodiversity in pushing the economic income of the community. Natural dyes batik can be a Indonesia flagship product particular Gunungkidul Regency in international market.
\end{abstract}

Key words: SMEs, batik, Manggar Gading, natural dyes

\section{PENDAHULUAN}

Batik merupakan warisan budaya nusantara yang memiliki nilai seni tinggi dan sarat akan makna filosofis. Masyarakat Indonesia sudah mengenal dan menggunakan batik sejak lama. Dahulu kain batik merupakan busana kebesaran keluarga kerajaan dan bangsawan, namun saat ini batik dapat digunakan seluruh kalangan masyarakat. Keberadaan batik sudah cukup dikenal di dunia internasional bahkan menjadi ciri khas bangsa Indonesia yang merupakan salah satu warisan turunmenurun. Batik mendapatkan pengakuan dari United Nations Educational Scientific and Cultural Organizaton (UNESCO) pada tahun 2009 (surya,2009). Setiap daerah di 
Indonesia memiliki batik yang mengambarkan motif dan corak khasnya masing-masing seperti, batik Solo, Pekalongan, Yogyakarta, Tasik, Madura, Bali, dan lain-lain.

Bahan utama yang dibutuhkan dalam membuat batik adalah kain, malam lilin dan pewarna kain. Sebelum adanya pewarna buatan (sintetis), batik diwarnai dengan pewarna alam yang dapat diperoleh dari alam disekitar kita. Pewarna alam memiliki warna khas yang unik dan membuat batik terlihat lembut, natural dan teduh. Pewarna alam dapat diekstrak dari tanaman, hewan, mikroorganisme, batu, dan tanah yang keberadaaannya melimpah di lingkungan sekitar (M. Shahid,2013). Negara Indonesia memiliki keanekaragaman hayati yang dapat dimanfaatkan sebagai sumber pewarna alam. Metode ekstraksi yang tepat dapat menghasilkan ekstrak pewarna alam dengan kualitas yang baik (Anastasia,2013). Penggunaan pewarna sintetis telah menggeser keberadaan pewarna alam yang memang pada awalnya digunakan pada proses pembuatan batik. Batik pewarna alam diklain sebagai salah satu komoditi/ produk yang lebih ramah lingkungan, dan memiliki nilai jual yang cukup tinggi. Persaingan global yang semakin kompetitif dan dinamis, menjadikan preferensi konsumen terhadap produk ramah lingkungan terus meningkat. Ini merupakan peluang besar bagi industri batik nasional untuk meningkatkan pangsa pasarnya .

Industri batik di Indonesia di dominasi oleh industri berskala UMKM. Berdasarkan data disperindakop D.I. Yogyakarta, industri batik terus mengalami pertumbuhan dengan jumlah UMKM yang mencapai 8000 UMKM pada tahun 2015. Jumlah tersebut meningkat dari tahun 2013 yang semula masih berjumlah 3000 UMKM yang tersebar di lima kabupaten di D.I.Yogyakarta (Yudha Manggala,2016). Gunungkidul merupakan salah satu daerah di provinsi D.I. Yogyakarta yang sektor pariwisatanya berkembang sangat pesat karena didukung potensi kekayaan alamnya yang besar. Daerah wisata merupakan pangsa pasar batik yang cukup menjanjikan. Di Kabupaten Gunungkidul sendiri terdapat UMKM batik yang setiap tahun jumlahnya meningkat dan sampai dengan tahun 2018 ada 25 UMKM batik yang tergabung dalam ASPETIG (Asosiasi Pengusaha Batik Gunungkidul Handayani). Sebagian besar UMKM batik ini masih memproduksi batik pewarna sintetis dan hanya sedikit yang memproduksi batik pewarna alam. Salah satu UMKM di Gunungkidul yang sudah cukup dikenal dengan produk batik pewarna alamnya adalah UMKM Ndaru Batik Collection. Termotivasi akan usaha melestarikan warisan budaya leluhur yang adiluhung, menjadikan UMKM Ndaru Batik Collection saat ini mampu memproduksi 200 - 300 potong kain batik setiap bulan dengan jumlah pekerja sebanyak 20 orang. UMKM tersebut merupakan salah satu contoh bukti pengembangan potensi ekonomi masyarakat yang tersimpan dalam karya budaya (Hernawan,2016).

Manggar Gading merupakan salah satu UMKM batik yang berlokasi di Dusun Gading I, Desa Gading, Kecamatan Playen. UMKM batik ini beranggotakan 22 orang yang memproduksi kain batik dengan teknologi sederhana. Komoditi utama UMKM Manggar Gading masih berupa kain batik dengan pewarna sintetis. Tujuan dari pelatihan ini adalah mengintroduksikan pewarna alam sebagai bahan pewarna batik kepada pengrajin batik di UMKM Manggar Gading sehingga dapat mengaplikasikan pada produk kain batik yang mereka produksi.

\section{SOLUSI/TEKNOLOGI}

Solusi yang ditawarkan dalam pelatihan ini antara lain memberikan pengetahuan tentang potensi bahan alam yang dapat dijadikan pewarna alam serta keterampilan dalam pembuatan/ ekstraksi zat warna alam dan penggunaannya dalam pewarnaan kain batik. Teknologi sederhana, tepat guna, dan secara teknis sesuai dengan kondisi real lapangan diterapkan pada pelatihan sehingga 
manfaatnya dapat langsung diperoleh peserta pelatihan.

Pelatihan dilakukan dengan penyampaian materi oleh narasumber kemudian dilanjutkan dengan praktek langsung olehnarasumberi dan peserta. Bahan yang digunakan pada pelatihan ini adalah bahan pewarna alam berupa indigo, tinggi, jambal, jalawe, tegeran dan secang. Bahan-bahan ini merupakan pewarna alam yang memang biasa digunakan untuk pewarnaan alam kain batik. Peralatan yang digunakan pada pelatihan ini merupakan peralatan proses pembuatan batik yang sudah dimiliki oleh UMKM Manggar Gading. Peralatan yang digunakan untuk pembuatan warna atau ekstraksi zat warna alam dan aplikasinya pada kain batik tidak berbeda dengan peralatan pada proses pewarnaan dengan pewarna sintetis.

\section{HASIL DAN DISKUSI}

\section{Survei Lapangan}

Survei lapangan dilakukan untuk mengumpulkan informasi tentang proses produksi batik di UMKM Manggar Gading melalui wawancara, diskusi, dan kunjungan lapangan. Hasil survei menunjukkan bahwa proses produksi batik di UMKM Manggar Gading masih menggunakan peralatan manual dan sederhana. Bahan pewarna yang digunakan dalam proses produksi selama ini merupakan zat warna sintetis seperti, naphtol, indigo sol, dan rapid. Pengrajin batik di UMKM Batik Manggar Gading belum mempunyai kemampuan dan pengetahuan tentang proses pembuatan bahan zat warna alam serta penggunaannya dalam pewarnaan kain batik. Keterampilan dan pengetahuan yang dimiliki pengrajin baru sebatas proses pembuatan batik cap dan tulis dengan pewarna sintetis. Produksi kain batik dilakukan oleh pengrajin berdasarkan pesanan (by order). Komoditi yang dihasilkan dari proses produksi masih berupa kain batik dengan pewarna sintetis.

\section{Kegiatan Pelatihan}

Ada dua jenis pelatihan yang diselenggarakan di UMKM Manggar Gading yang diikuti oleh 22 orang anggota perkumpulan Manggar Gading Gunungkidul. Peserta pelatihan diberikan pengetahuan tentang potensi bahan-bahan alam yang dapat digunakan sebagai pewarna batik, cara mengekstrak/ membuat pewarna alam, serta aplikasinya pada pewarnaan kain batik. Setiap pelatihan dibagi menjadi dua sesi, yaitu sesi pertama berupa penyampaian materi secara teoritis kemudian dilanjutkan sesi kedua dengan praktek bersama.

Pelatihan pertama diselenggarakan selama dua hari dengan materi pembuatan/ ekstraksi pewarna alam. Pengrajin diberikan informasi mengenai berbagai macam bahan alam baik dari bahan flora, fauna, dan mikrobia yang dapat digunakan sumber zat warna alam. Bahan alam yang sudah biasa digunakan sebagai pewarna kain adalah tanaman seperti mahoni, nila/ indigo, soga, tingi, somba, jati, secang, tenggeran, kunyit, henna, mengkudu, jambu biji, jati, dan lainlain. Bagian tanaman yang digunakan dapat berupa akar, daun, bunga, biji, batang, kulit kayu, buah, dan bunga. Masing-masing bahan alam ini memiliki karakteristik yang berbeda sehingga cara ekstraksi zat warnanya juga berbeda. Pengetahuan tentang jenis pelarut dan metode ekstraksi juga disampaikan pada pelatihan ini. Ada dua jenis pelarut yang digunakan untuk mengekstraksi zat warna alam, yaitu pelarut organik dan pelarut air. Ada berbagai macam metode ekstraksi pewarna alam, antara lain maserasi, infundasi, perkolasi, dan soxlet. Untuk mendapatkan ekstrak zat warna alam berkualitas, diperlukan pemilihan metode ekstraksi zat warna alam yang tepat. Air merupakan pelarut yang biasa digunakan untuk mengekstrak zat warna alam yang digunakan dalam pewarnaan kain batik Pelatihan difokuskan pada penggunaan pelarut air dan metode perebusan dengan pertimbangan hasil, efisiensi, ketersediaan alat dan bahan serta kemudahan dalam teknis pelaksanaannya.

Pelatihan kedua diselenggarakan selama tiga hari dengan materi penggunaan 
zat warna alam untuk pewarnaan kain batik dan juga praktek pembuatan kain batik dengan pewarna alam. Pada sesi praktek, peserta pelatihan dibagi menjadi beberapa kelompok agar peserta menjadi lebih fokus pada tiap tahapan proses pembuatan batik pewarna alam. Diskusi tentang penggunaan zat warna alam dalam pewarnaan kain dilakukan pada saat peyampaian materi secara teori dan juga pada ssat kegiatan praktek. Proses produksi kain batik terdiri dari beberapa tahap yaitu mordanting, menggambar pola, pembatikan (menutup pola dengan malam/ lilin), pencelupan/ pewarnaan, pelorotan, fiksasi, dan pencucian. Mordanting bertujuan untuk membersihkan kain dan membuka pori kain sehingga zat warna meresap pada kain. Proses mordanting dilakukan selama 24 jam. Bahan yang dibutuhkan untuk proses ini antara lain TRO, tawas, dan soda abu.

Beberapa pewarna alam yang pakem/ biasa digunakan oleh pengrajin batik dengan pertimbangan ketersedian bahan dan sifat warnanya (keawetannya) setelah diaplikasikan ke kain. Bahan pewarna tersebut, antara lain tegeran, tinggi, jolawe, jambal, dan indigo. Komposisi campuran ekstrak zat warna alam diperlukan untuk mendapatkan warna yang diinginkan pada saat digunakan dalam pewarnaan kain batik. Teknik pencelupan atau pewarnaan dengan zat warna alam pada kain konsepnya hampir sama dengan pewarna sintetis. Salah satu kelebihan penggunaan zat warna alam pada proses ini adalah tidak memerlukan

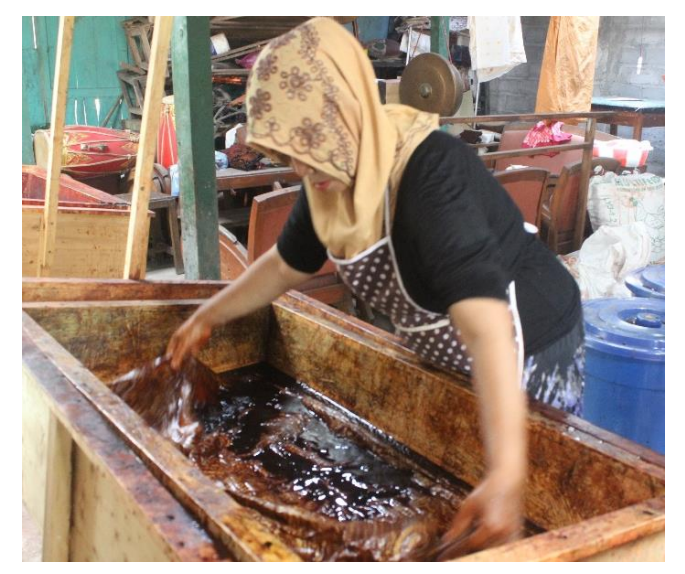

pembilasan disetiap kali pencelupan, sehingga lebih menghemat air. Setiap kali proses pencelupan atau pewarnaan kain dengan perwarna sintetis, diperlukan pembilasan untuk menghilangkan sisa pengotor/ endapan zat warna yang menempel pada kain. Keunggulan lain dari penggunaan zat warna alam adalah sisa bahan zat warna alam masih dapat digunakan untuk proses selanjutnya (tidak dibuang) dengan syarat sisa bahan tersebut disimpan dengan baik. Pada proses finishing, penggunaan jenis fixer (pengunci warna) juga mempengaruhi warna batik yang dihasilkan.

Sesi diskusi juga dilakukan setelah praktek proses pembuatan kain batik dengan pewarna alam selesai dilaksanakan. Diskusi ini membahas tentang beberapa permasalahan/ kesulitan yang terjadi pada saat praktek proses pewarnaan (pencelupan), penjemuran, pelorotan, dan fiksasi. Pengrajin menyampaikan pendapat mereka tentang beberapa perbedaan yang dirasakan selama proses pembuatan batik dengan zat warna alam dibandingkan dengan zat warna sintetis. Kelebihan dan kekurangan baik tentang proses pembuatan maupun produk batik zat warna alam dipaparkan oleh peserta pelatihan. Hasil pelatihan ini menunjukkan bahwa antusiasme pengrajin batik UMKM Manggar Gading dalam pembuatan batik zat warna alam cukup tinggi. Pengrajin UMKM Batik Manggar Gading sudah dapat membuat/ memproduksi batik zat warna alam.

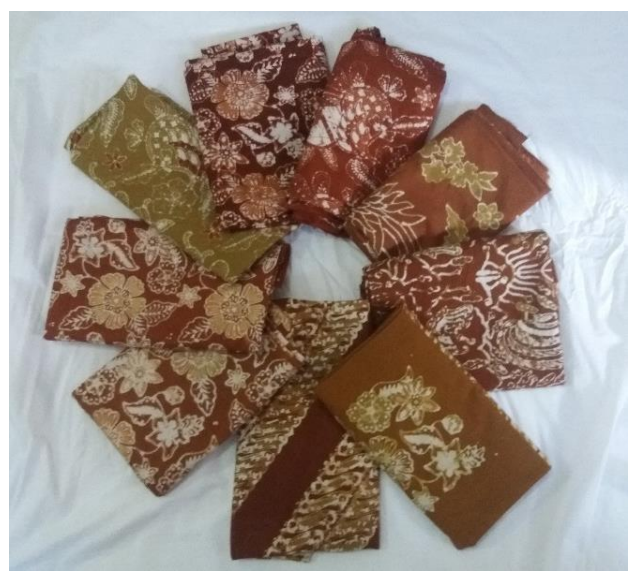

Gambar 2. (a) Proses pencelupan/ pewarnaan kain batik zat warna alam 


\section{KESIMPULAN}

Pelatihan pembuatan zat warna alam dan aplikasinya untuk batik telah dilaksanakan di UMKM Batik Manggar Gading. Peserta pelatihan pada akhir kegiatan telah mampu membuat zat warna alam dan juga menggunakannya sebagai pewarna kain batik. Pelatihan ini dirasakan sangat bermanfaat bagi peserta terutama dalam peningkatan pengetahuan, pengalaman, dan ketrampilan dalam pembuatan batik zat warna alam.

\section{UCAPAN TERIMA KASIH}

Ucapan terima kasih diberikan kepada Program Prioritas Nasional Lembaga Ilmu Pengetahuan Indonesia 2018 yang telah mendanai kegiatan ini dan UMKM Batik Manggar Gading atas partisipasinya.

\section{PUSTAKA}

Surya, "Batik Indonesia Resmi Diakui UNESCO," Antara, Jakarta, 02-Okt2009.

M. Shahid, Shahid-ul-Islam, dan F. Mohammad, "Recent advancements in natural dye applications: a review," J. Clean. Prod., vol. 53, hlm. 310-331, Agu 2013.

Anastasia Wheni Indrianingsih dan Cici Darsih, "Natural Dyes from Plants Extract and Its Applications in
Indonesian Textile Small Medium Scale Enterprise," J. Prodi Tek. Kim. UPN Veteran Yogyak., vol. 11, no. 1, hlm. 16-22, Jun 2013.

"Pewarna Alam Batik Kurangi Impor Sintetik," Kemenperin.

Yudha Manggala P Putra, "Perajin Batik DIY Didorong Tingkatkan Daya Saing," Republika, Yogyakarta, 22Mar-2016.

Hernawan dan Cici Darsih, "Evaluasi Manajemen Inovasi Berbasis Green Material Melalui Iptekda LIPI pada Industri Batik Tancep," J. Penelit. Dan Pengemb., vol. 5, hlm. 51-57, 2014.

Tilani Hamid S dan Dasep. Muhlis, "Perubahan Sifat Fisika dan Kimia Kain Sutera Akibat Pewarna Alami Kulit Akar Pohon Mengkudu," J. Teknol., vol. 29, no. 2, hlm. 163170, 2005.

Iftitah Ruwana, "Pengaruh Fiksasai Terhadap Ketahanan Luntur Warna pada Proses Pencelupan Kain Kapas dengan Menggunakan Zat Warna dari Limbah Kayu Jati," J. Teknol. Kejuru. Dan Pengajarannya, vol. 3, no. $1,2008$.

S.K. Sewan Susanto, Seni kerajinan batik Indonesia. Yogyakarta: Balai Penelitian Batik dan Kerajinan, Lembaga Penelitian Industri, Departemen Perindustrian, 1973. 